\title{
MOBILIARIO E INTERIORES EN LOS COMEDORES DE FONDAS Y HOTELES DE ENTRE-SIGLOS EN ASTURIAS. NUEVOS ESCENARIOS PARA LA RELACIÓN SOCIAL. \\ FURNITURE AND INTERIOR DESIGN IN HOTEL AND INN'S DINING ROOMS IN ASTURIAS BETWEEN THE LATE XIX ${ }^{\text {th }}$ AND THE EARLY XX ${ }^{\text {th }}$ CENTURIES: NEW SCENES FOR SOCIAL RELATIONSHIP
}

Gracia Suárez Botas* Universidad de Oviedo

\section{Resumen}

Partiendo de las transformaciones de las últimas décadas del siglo XIX y de la aparición del concepto de confort, el artículo analiza los cambios que se van produciendo en los comedores de los nuevos hoteles y fondas asturianas al ir ajustándose a nuevos usos y hábitos sociales. Un recorrido que nos acerca al mobiliario y al equipamiento de unos establecimientos que se adaptan a sus nuevas funciones y reflejan el gusto y los criterios estéticos de su nueva clientela.

Palabras Clave: Hotel, comedores, confort, hábitos sociales, mobiliario.

\begin{abstract}
Based on the changes of the last decades of the nineteenth century and the emergence of the concept of comfort, the article examines the changes that have taken place in restaurants and canteens in the new hotels in Asturias in order to adjust to new uses and social habits. A journey that brings us to the furnishing and out fit of some establishments that adapt to their new roles and reflect the taste and aesthetic criteria of its new customers.
\end{abstract}

Key-words: Hotel, dining room, comfort, social habits, furniture.

En el siglo XIX asistimos a un conjunto de transformaciones cruciales en la sociedad que van a desembocar en la aparición de unos establecimientos dedicados al hospedaje de viajeros muy renovados, que suponen una auténtica transformación respecto a los modelos anteriores.

*E-mail: gsuarez@facultadturismo.com 
Por un lado la revolución de los transportes, especialmente la aparición del ferrocarril y la mejora de la red viaria, con nuevos caminos de ruedas asociados al desarrollo de las compañías de diligencias, había propiciado la generalización de líneas regulares para el pasaje de viajeros en la segunda mitad del siglo XIX. Sirvió todo ello para activar al conjunto de las poblaciones asturianas, y romper el aislamiento en que se vivía en muchas de ellas, estimulando la aparición de empresas de transporte de mercancías y de viajeros, que desarrollaron así el comercio e hicieron posible un aumento del tráfico. Todo ello va a favorecer la aparición de nuevas fondas, que poco más tarde desembocarán en los hoteles, y que con nuevos equipamientos y servicios más exigentes sustituirán a los antiguos mesones, ventas y posadas.

También los modos de producción artesanal en el campo del mueble iban a dejar paso durante esos años a la incorporación de procedimientos mecánicos en su fabricación, que van a hacer posible una estandarización y una diversificación del mobiliario. Es en las últimas décadas de siglo cuando asistimos a la generalización de talleres mecanizados de cierta envergadura y a la aparición de firmas comerciales vinculadas al sector de la ebanistería capaces de diseñar y asumir proyectos decorativos completos ${ }^{1}$. No va a ser Asturias una excepción, máxime si tenemos en cuenta el papel desempeñado por esta región en los inicios de la industrialización española, y buen exponente de ello es la celebración en Gijón de la Exposición Regional de 1899, fiel escaparate del progreso de la industria regional ${ }^{2}$.

Asimismo se van a producir avances tecnológicos que van a introducir cambios trascendentales en las condiciones de la vida doméstica. La mejora de las instalaciones sanitarias, el progreso de la iluminación con la llegada de la electricidad, el ascensor, el teléfono, son los principales servicios y equipamientos que, si se van a ir incorporando a la vivienda burguesa, transformando hábitos de vida y conductas domésticas, con más motivo lo harán en los hoteles y fondas, donde ofrecerán a los clientes el "confort moderno", tan característico de los nuevos tiempos ${ }^{3}$. Antes de 1870, el confort, término que se aclimata y define en el s. XIX, apenas había progresado. Las habitaciones tenían como principales atributos su amplitud y buena ventilación, con luz directa del exterior abriéndose a la calle mediante amplios balcones, algo que va a seguir siendo fundamental durante mucho tiempo, llegando a ser elemento esencial de las tipologías arquitectónicas más repetidas para las nuevas fondas y hoteles.

Realmente la relación entre ventilación y salud se asocia a un peculiar discurso higienista propio de la mentalidad del siglo XIX. El aire viciado de los interiores era considerado como la causa directa de todo tipo de epidemias y de las enfermedades más comunes en aquellos tiempos. "Ningún libro del siglo XIX sobre la planificación doméstica se consideraba completo si no incluía por lo menos un capítulo sobre el tema de la ventilación y los perjuicios del aire viciado (...) el siglo XIX enfocaba el problema del aire de forma científica..." 4 . La preocupación por el efecto perjudicial del dióxido de carbono en los interiores, llevaba a arquitectos, ingenieros y científicos a recomendar introducir en la casa enormes cantidades de aire libre. De ahí que las referencias que aparecen en los 
anuncios publicitarios de hoteles y fondas de esta época a "habitaciones ventiladas" constituyan una auténtica constante en esos años que van desde las últimas décadas del siglo XIX hasta las primeras del XX. Sin embargo apenas se buscaba aislar las habitaciones de las vecinas; por el contrario, estaban muchas veces comunicadas, y las puertas, así como los estrechos tabiques dejaban pasar el ruido. Las piezas estaban preparadas, en realidad, para que, uniendo unas y otras estancias, pudiesen funcionar como verdaderos apartamentos para el servicio de las familias. De este modo, el servicio de habitaciones podía transformarse y parecerse, con sus habitaciones italianas, espacios comunicados y gabinetes, a uno de los muchos interiores burgueses que se estandarizan en el siglo XIX, y en donde la intimidad de las familias, a salvo de indiscreciones del servicio doméstico, se preservaba mediante la interconexión de las piezas de habitación o con pequeñas salitas de confianza; quedando el pasillo para el uso de un servicio atento a cualquier requerimiento que en el hotel se les hiciese a través del sistema de timbres. De hecho, el alojamiento de familias constituye una parte muy importante de la demanda hotelera en la Asturias de la época.

Con el tiempo, sin embargo, el deseo de intimidad individual y el desarrollo cada vez mayor de una clientela vinculada a los negocios, y que en consecuencia solía viajar sin la familia, contribuyó a dotar de un nuevo sentido a las demandas de aislamiento en la habitación. El emblema de esta intimidad y aislamiento individualista pasó a ser, en muchos sentidos, el silencio; o si se prefiere, la imposibilidad de que el ruido invadiera la soledad y el retiro confortable del cliente en su habitación.

El nuevo valor del silencio aparece contemplado por la fina sensibilidad de Azorín en el texto que se reproduce a continuación, en el que el autor también introduce acertadas recomendaciones sobre cómo debe ser el mobiliario y el equipamiento de los nuevos hoteles:

"Hoteleros: Lo primero que debéis procurar es tener una cosa esencial, esencialísima, en vuestros hoteles..-¿Qué cosa es ésa, señor cronista?-Esa cosa tan necesaria y trascendental es... el silencio.

Se hace un hotel nuevo: se construye con planos adecuados; se compran muebles elegantes y cómodos; se procura que la cocina la rija un excelente, peritísimo maestro; se allega un personal de servidumbre solícito y amable...Todo, todo está previsto; en todo se piensa; para todo hay cuidado..., menos para el silencio. En los hoteles buenos de Londres, detrás de las puertas hay unos pequeños hilos de goma, a fin de que las puertas se detengan en ellos y no choquen ruidosamente con la pared al ser abiertas con ímpetu. En los hoteles de Londres, los timbres que hay en los pasillos, y que son utilizados constantemente, tienen un son apagado, sordo, de madera más que de metal. (En realidad, los timbres deben suprimirse; el teléfono puede sustituirlos) pero en España no entramos en esas delicadezas, no las comprendemos...; no reparamos estas cosas, en los innumerables pequeños engorros, ruidos, olores y desarreglos de los hoteles. Aún en los más lujosos son visibles el desorden y la despreocupación. Hace poco nos hallábamos en uno de los más lindos y cómodos hoteles de San Sebastián; estábamos en el salón central de la casa, y durante una 
hora estuvimos oyendo el son de un piano..., que también se oía en muchas de las habitaciones del hotel. Hoteleros: procurad a toda costa el silencio. Nada de timbres ruidosos, ni de carreras de los criados por los pasillos, ni de charlas durante la noche en los corredores, ni de estrépito de vajilla, ni de pianos, ni de portazos violentos. Procurad la limpieza; todo blanco, sencillo y limpio. Nada de pesados cortinajes; nada de muebles complicados y ridículos. Haced que los criados sean diligentes y dóciles; lo más desagradable en un hotel, y en todas partes, es confiar en un encargo que se ha dado a un servidor... y que no se ha hecho. Estamos en el cuartito de la fonda, de noche. No conocemos la ciudad. ¿Hacía donde caerá este hotel? ¿Adónde darán las ventanas de este cuartito? Cuando nos levantamos por la mañana -joh alegría!-, abrimos las maderas y vemos un reducido y solitario jardín, o la perspectiva de una montaña o la lontananza del mar. El hotel tiene un ancho vestíbulo, donde podemos reposar en cómodos y ligeros sillones. Hay periódicos y revistas que no son atrasados; no suenan pianos; no suenan timbres; no discuten servidores" 5 .

Son muchas las transformaciones que se van a producir en estos años en los edificios destinados a viajeros. Especialmente porque ya no eran los arrieros y trajinantes sus principales huéspedes, sino una distinguida clientela asociada a actividades comerciales y profesionales, también algunos turistas, como también lo hará un público familiar de clase media que va a vivir en el hotel. Surgen nuevos lugares de representación y de relación necesarios para un nuevo concepto de vida en el hotel: amplios halls, salones, gabinetes de trabajo para los viajantes, habitaciones italianas.

Pero si tenemos que elegir el espacio que mejor resume las costumbres asociadas a la sociabilidad decimonónica, es sin duda el comedor de la fonda o del hotel, un lugar donde se va a ritualizar la costumbre de la mesa redonda, donde todos los comensales van a compartir tanto mesa como conversación en un clima marcado por una rígida etiqueta ${ }^{6}$. Las mesas redondas estuvieron en uso en la mayor parte de los hoteles hasta los comienzos del siglo XX y su denominación, table d'hôte, refleja su origen y la influencia francesa en el mundo del hotel.

Este estudio se basa en el análisis de un conjunto de establecimientos de hospedaje asturianos, en el que se incluyen desde hoteles de lujo hasta modestas pero afamadas fondas. Y sea cual sea la naturaleza y las características del establecimiento, el comedor va a ser la pieza clave del edificio.

Un indicio de su importancia lo constituye la observación de los numerosos comedores que nos ofrece el Álbum Anunciador de Asturias del año 18937, con unas imágenes que se acercan a la realidad de un equipamiento y decoración propio del último cuarto del s. XIX, y que evocan una situación que va a cambiar muy pronto. Aparecen en esta obra los comedores de los hoteles Colunguesa, Trannoy, Francés y Del Casino, en Oviedo, más algún otro de la provincia como la Fonda Belaústegui de Infiesto; que con más o menos lujo en cuanto a decoración y mobiliario, presentan muy parecida disposición. Son todas ellas estancias amplias, pero no grandes; de techos altos, con ventanas en alguno de sus lados, y con las clásicas columnas de fundición de apoyo al sistema de vigas, bien ornamentadas ${ }^{8}$.Ocupadas de lado a lado por una o por dos monumentales mesas 
alargadas (las denominadas mesas redondas), donde todos los comensales compartían menú y conversación, siguiendo unos estrictas normas de etiqueta. Alrededor de la mesa se disponían las clásicas sillas thonet, fuera cual fuera la categoría del lugar9. Estas sillas, van a ser el elemento más característico del amueblamiento de hoteles y fondas de finales de siglo. Su lugar va estar ligado especialmente al comedor, aunque también pueden aparecer en la habitación o en otras dependencias. Desde el punto de vista estructural, esta silla de origen vienes, saca partido de la técnica del curvado al vapor de la madera, generalmente de haya. Por la forma curva de su respaldo proporciona comodidad y el asiento, de rejilla de fibra vegetal, cumple con los criterios higienista de la época, máxime cuando se trata como en este caso de establecimientos públicos, con lo que esto supone de uso masivo y prolongado ${ }^{10}$.

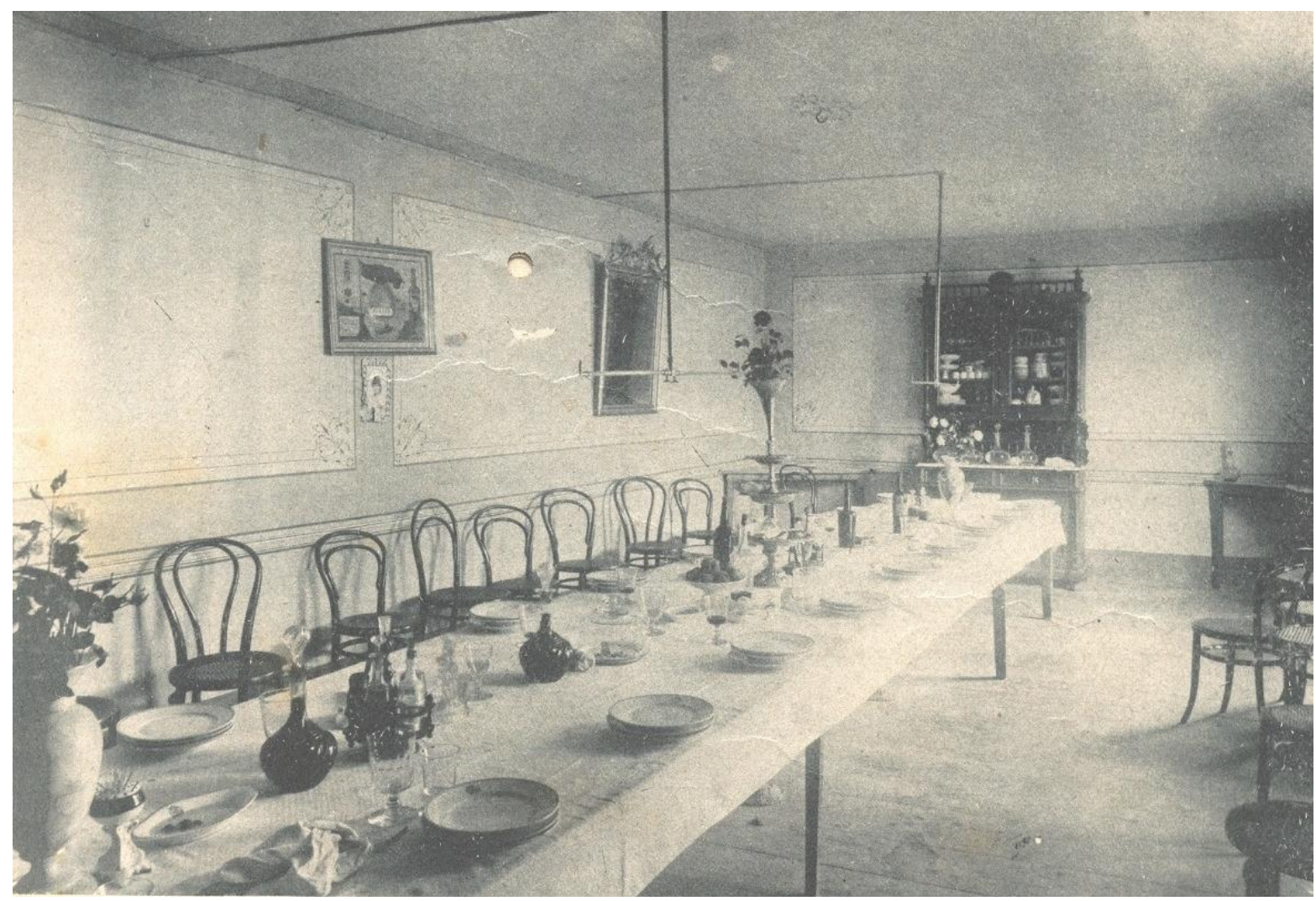

Fig. 1. Comedor de la fonda del Casino en Oviedo. (Álbum Anunciador de Asturias, 1893)

El resto del mobiliario y decoración en estos comedores, va estar marcado por la categoría del establecimiento. De este modo, hoteles más exclusivos como la Colunguesa, el Trannoy o el Francés, con sus papeles pintados, lujosos espejos, revestimientos murales, y también con la decoración y menaje de sus mesas, marcaban las diferencias y ofrecían un acogedor aspecto, mientras que otros como el del Casino o la fonda de Baláustegui, con sus austeras paredes blancas salpicadas de algún que otro cuadro o cartel publicitarios, se acercan a un modelo más modesto que se repetiría por toda la geografía asturiana. Es en estos comedores donde vamos a ver aparecer una serie de elementos de mobiliario con una funcionalidad estrechamente ligada al servicio de comedor. Trincheros, 
mesas auxiliares y aparadores vitrina, constituyen un auténtico referente; son piezas claramente determinadas en su estructura por su utilidad, pero con continuas concesiones a criterios ornamentales historicistas; el aparador para la vajilla y otros enseres, podía tener la misma apariencia de los utilizados en los comedores de uso familiar, con armario en la parte inferior y vitrina superior; pero también vemos aparecer en comedores mejor equipados algunos muebles realizados a medida. Es el caso del hotel Francés en Oviedo, un establecimiento que se abre en el año $1883^{11}$ en el Campo de la Lana, lugar de paradas de diligencias, ocupando un edifico construido exprofeso para hotel, bajo proyecto del arquitecto Javier Aguirre, donde también se encontraban los despachos de las principales compañías de diligencias ${ }^{12}$. La imagen que nos ofrece este interesante álbum publicitario ilustrado de este comedor, muestra un alargado aparador vitrina de sencillas líneas, en disposición paralela a la table d’hôte, perfectamente combinado con el que se encuentra al lado del gran espejo. Lo mismo ocurre con el del hotel Trannoy, también de Oviedo, donde se alojaban los toreros ${ }^{13}$, un restaurante donde la zona de servicio y de acceso a la cocina se separa de la de los clientes, con dos muebles aparadores a medida, con estanterías para las botellas, que dan cómodo servicio a las dos mesas redondas que se disponen de forma perpendicular.

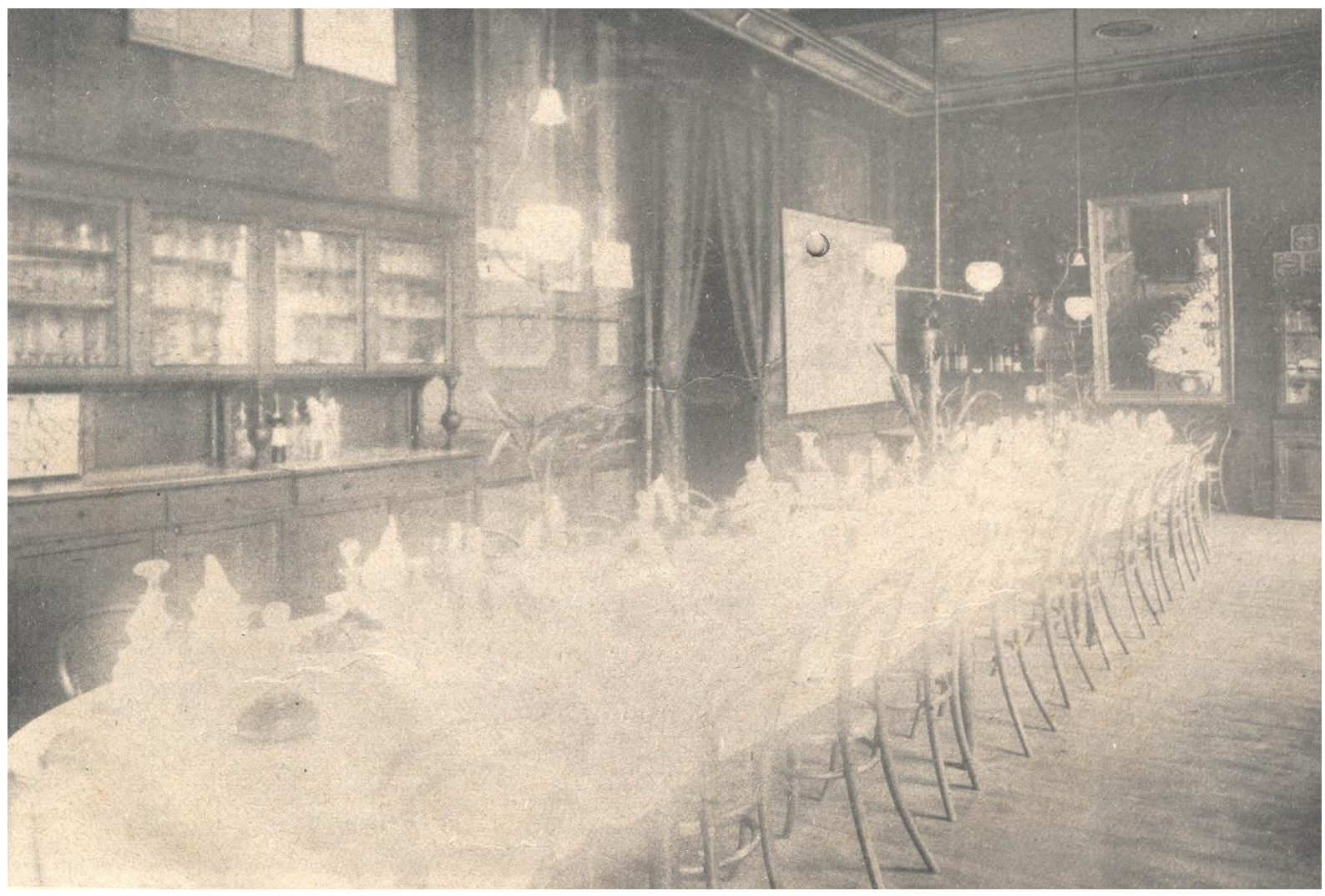

Fig. 2. Comedor del hotel Francés de Oviedo. (Álbum anunciador de Asturias, 1893) 
Estos locales decimonónicos no eran lo suficientemente amplios, y los banquetes multitudinarios se servían en estos años en los teatros, cines, o espacios de similar cabida ${ }^{14}$. La introducción de espejos, corriente en estos lugares o en los cafés más afamados, cumplía la función de multiplicar el espacio, contribuyendo así a una sensación de mayor desahogo.

Conviene comentar también que en esta primera generación de hoteles, el comedor se va a encontrar en muchos casos en el piso superior, y que este modelo va a perdurar por lo general sobre todo en establecimientos más modestos ${ }^{15}$. Había sucedido lo mismo, por cierto, con los primeros cafés; como es el caso del legendario Café de Chúcharo en la ovetense calle de la Rúa, citado por Constantino Cabal ${ }^{16}$. Los hoteles más lujosos, en cambio, adoptaron rápidamente la planta baja para sus comedores, aunque habrá desde luego excepciones como la del hotel Covadonga de Oviedo, uno de los mejores de la provincia, si no el mejor, que por el hecho de compartir sus locales en el mismo edificio del palacio del Banco Asturiano, va a instalar sus lujosos comedores en el piso principal. Lo mismo ocurriría con el hotel Inglés, antiguo establecimiento de primer orden de la familia Manteola, en cuya planta baja se encontraba la acreditada casa de pañería fina y paños ingleses de Natalio Martín.

El hecho de que el comedor se encuentre en la planta baja supone una comodidad para el cliente, especialmente para el que no se aloja en el hotel. El modelo fomenta de hecho el hábito social que ahora se inicia muy tímidamente de comer fuera de casa. Nada de extraño tiene, por tanto, que sea ésta la distribución elegida en los edificios que de nueva planta se construyen para hotel.

De este modo aparece señalado en la publicidad del hotel Comercio de Gijón, del año 1897, donde se lee "en la planta baja [de] comedor y Restaurant"17; al mismo tiempo que se destacan otras cualidades del negocio como el ser de primer orden, poseer ventiladas habitaciones, cocina francesa y española, etc. Porque, además, este establecimiento ya en 1891, ofrecía dos modalidades de servicio de cocina: la de un "Espacioso comedor, adornado con el mayor gusto y alumbrado con luz eléctrica", y la de un "Restaurant al lado del comedor, donde se sirven toda clase de platos desde los más modestos hasta los más espléndidos"18. Teniendo en cuenta las costumbres de la época, es fácil suponer que el comedor al que se refiere el anuncio incluiría la mesa redonda con un menú a unas horas preestablecidas, y que el restaurant sin embargo, ofrecería mesas independientes y un servicio más flexible.

Esta duplicidad de espacios será también una constante durante todo este periodo. Aunque más que esa distinción entre comedor y restaurante a la que se acaba de aludir, lo que se repetirá con frecuencia como consecuencia de la clara segregación social de estos lugares públicos, será la existencia de un comedor de segunda más pequeño y pobre en su equipamiento, pegado generalmente a la cocina. Se encuentra, desde luego, en algunos balnearios como en Las Caldas, y también en hoteles pequeños como el Victoria de Llanes, que acogía a una clientela de variada procedencia ${ }^{19}$, así como en la Fonda la Paca de Boal, con un comedor popular para tratantes de ganado en frente del bar tienda y otro rodeado de un mobiliario burgués cerca de las habitaciones ${ }^{20}$. 
El comedor va a ir cobrando importancia y se irá ampliando de modo que pueda dar cabida a una demanda creciente de banquetes, en vinculación directa con las nuevas costumbres, cada vez más volcadas a la vida de relación pública y con unos estándares de mayor consumo que hacen de ellos lugares muy frecuentados. Tal es así que el hotel París, al renovarse poco después de 1910 cuando fue adquirido por el hotelero Manuel del Valle, amplía de forma considerable sus comedores. Y lo mismo hará el Gayoso de Luarca, modificando la disposición de sus locales y la del pequeño comedor al que se entraba desde el callejón lateral21, que se amplía ocupando el resto de la planta, desplazando así al café, ubicado en el frente principal. Cuando en el año 1916 el gijonés hotel Malet se traslada a su nuevo emplazamiento en la calle Corrida, las reformas que hace el arquitecto Manuel del Busto en los locales que habían sido del antiguo Colón, convierten el comedor en el lugar más exquisito del establecimiento, como se va a ver más tarde. También es por estas fechas cuando el hotel La Serrana de Avilés se hace con la propiedad del inmueble e incorpora la planta baja, donde hasta entonces había estado instalado el Círculo Industrial y de Sport; trasladando allí un comedor que va a tener una hermosa fachada a la calle de la Muralla.

La conclusión de todo ello va a ser que el comedor irá ocupando un lugar privilegiado dentro del edificio pasando a ser la estancia más luminosa y amplia del hotel o fonda. Con orientación preferentemente sur y con grandes ventanales a una o dos fachadas principales, que jerarquizaba los espacios del hotel incluso en el caso de ocupar el primer piso; situación que hará que se opte frecuentemente por ocupar el chaflán para aprovechar el máximo de luz.

Desde los primeros años del siglo XX la mesa redonda o table d'hôte había empezado a ser sustituida por las pequeñas e independientes, y el aspecto que presentaban estos comedores era, de este modo, algo distinto a los descritos con anterioridad. El espacio interior va a estar ahora dominado por mesas de cuatro plazas, con manteles blancos, sillas thonet entre otras, buenas vajillas y cristalerías, suelos de losetas hidráulicas de bonitos dibujos, cortinajes y mucha luz y vegetación, entre la que vuelven a encontrarse sobre todo palmeras. Van a seguir siendo una constante las columnas de fundición, los grandes espejos y se va a diversificar el mobiliario, constituido principalmente por todo tipo de trincheros, aparadores, vitrinas y bufetes, con una fuerte presencia del estilo restauración. Y la boiserie -zócalo de madera- que comienza a recorrer la parte inferior de la paredes y cuyo uso se extenderá a los espacios más elegantes y acogedores de todo el siglo $\mathrm{XX}^{22}$.

Un primer ejemplo de estos comedores lo tenemos en la tarjeta postal del comedor del primitivo Malet de 1904, que a pesar de haber incorporado las mesas independientes, (detalle importante que aparece destacado en la información de la postal) recuerda todavía mucho a aquellos espacios decimonónicos de altos techos, columnas de fundición, espejos muy inclinados adornando muros, habiéndose incorporado aquí, una mampara con decoración modernista separando dos ambientes, muy utilizada en estos años para separar dividir dos zonas o para recrear ambientes de cierta intimidad para los usuarios ${ }^{23}$. 
La decoración de interiores en las dos primeras décadas de siglo se va haciendo más sofisticada, y los espacios algo desangelados del XIX, van a dar paso a acogedores estancias con molduras, adornos y apoyos de referencias clásicas, que incorporan una mayor diversidad en el estilo de su mobiliario. La conquista del confort decimonónico, traducida en un mayor y más especializado acopio de muebles, y que se había afirmado en los interiores burgueses progresivamente, se traslada ahora a unos locales de reunión que cada vez tienen un papel mayor en los ritos y representaciones públicas de una burguesía en franca expansión ${ }^{24}$.



Fig. 3. Comedor del hotel Malet. Gijón. (Archivo del Museo del Pueblo de Asturias)

Son abundantes las imágenes conocidas de interiores de comedores que se corresponden con algunos de los mejores establecimientos de la región; circunstancia lógica si se considera el valor emblemático que tenían estos espacios en la fisonomía comercial del hotel y, por tanto, su lógica presencia en la propaganda de estas empresas. Se conoce la distribución de estos interiores en casos como los del viejo y nuevo Malet, Covadonga, París o Gayoso.

Uno de los mejores ejemplos lo constituye el restaurante del nuevo hotel Malet, obra del arquitecto Manuel del Busto, cuya tarjeta postal muestra el magnífico aspecto que tenía este espacio de estética clasicista en la línea del gusto Beaux-Arts ${ }^{25}$. Este estilo, utilizado para un diseño de interiores suntuoso, e inspirado en la arquitectura neoclásica francesa de los siglos XVII y XVIII, se basaba en las enseñanzas de L'École de Beaux-Arts de París y su influencia, que ocupa la segunda mitad del s. XIX, perdura hasta la Segunda Guerra Mundial. En Gran Bretaña, el más destacado exponente de este estilo fue la firma Mèwes and Davis (1900-1910), que diseñó el Hotel Ritz de Londres y el de Madrid, de 
moda entonces en la decoración de hoteles de lujo, siguiendo la misma grandiosa concepción arquitectónica que se observa también en el hall y el salón ${ }^{26}$. Gruesos pilares con acabado de pilastras estriadas y capiteles jónicos, columnas de fustes lisos, varios tipos de molduras y otros adornos formaban parte de este repertorio decorativo en el nuevo comedor del Malet. El suelo era de cálida madera, y el mobiliario, el más refinado de los hoteles asturianos, de influencia inglesa, perceptible en detalles como la presencia de sillas neo-hepplewhite. Destacaba así mismo la presencia de unas elegantes vitrinas con fondo de espejo y sencillos remates curvos.

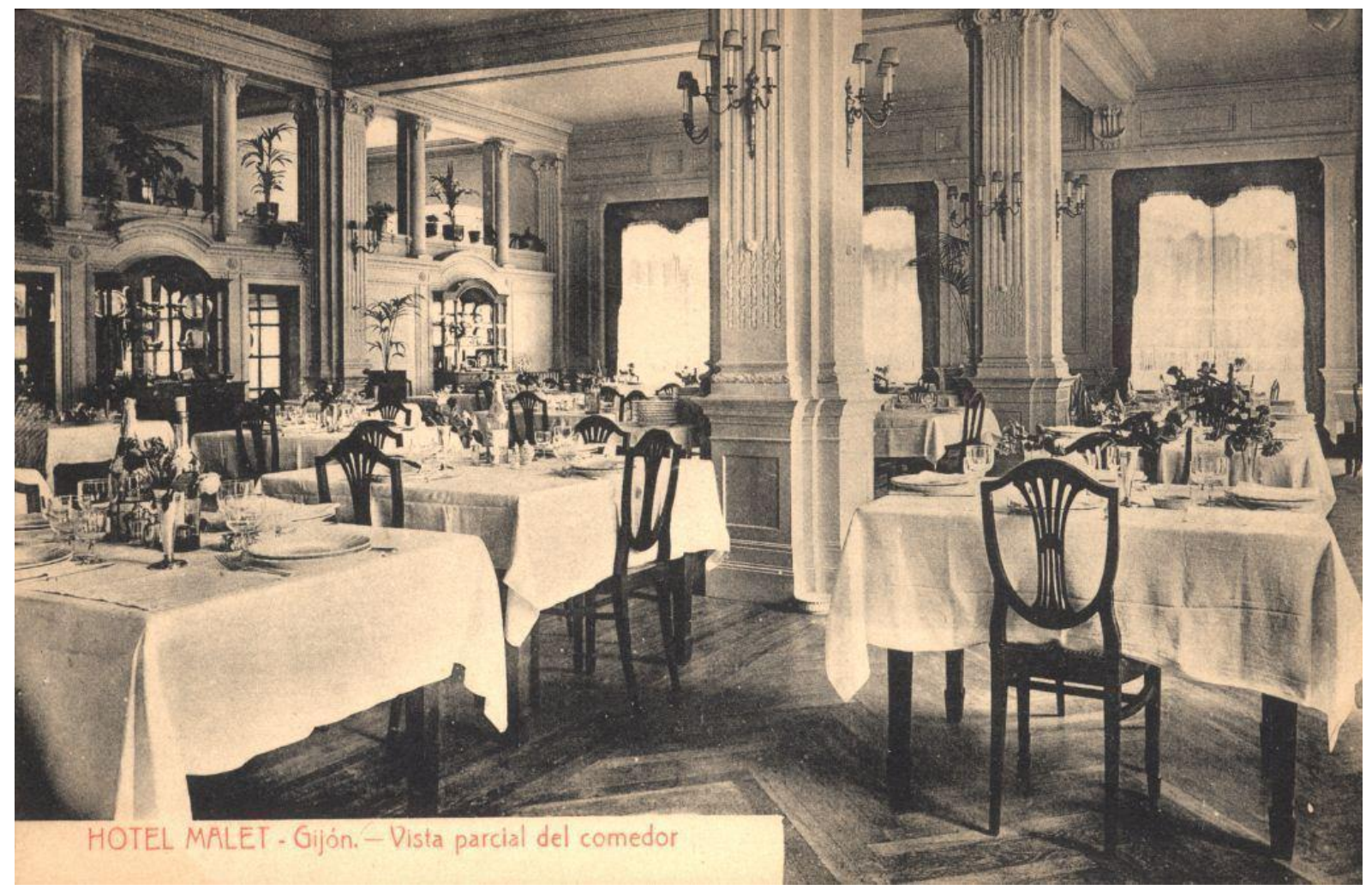

Fig. 4. Restaurante del nuevo hotel Malet de la calle Corrida. (Archivo Municipal de Gijón)

Del Nuevo Hotel París, sobre el pasaje de la calle Uría de Oviedo, se conocen varias imágenes de su comedor, tras la importante reforma del hotel en la década de $1910^{27}$. Con un gran frente de ventanal hacia el parque de San Francisco, principal zona de paseo de la capital, se adornaban sus muros y techo con decoración menuda y una greca con motivos de lazos y círculos de filiación modernista, así como pilares y pilastras con molduras de escayola de decoración más clásica. Los suelos se cubrían, con la habitual baldosa hidráulica con motivos geométricos, estando el mobiliario de la sala compuesto de grandes aparadores armario y una sillería con respaldo curvo de cuero. La modernización del hotel suponía entonces abrir nuevos espacios para la relación social de la selecta clientela, como el coqueto hall bajo la cristalera del pasaje para organizar "tés selectos", la terraza sobre el paseo de los Álamos, así como la brasserie, pensada para un público masculino ${ }^{28}$. 
En el hotel Covadonga, el art-nouveau está presente en la decoración mural, con frisos de gran movimiento y guirnaldas en el techo, así como lámparas de largas varillas de vidrio, lo que contrasta con la sobriedad del mobiliario de sus trincheros y aparadores acompañados de grandes espejos. Las columnas de fundición profusamente decoradas con temas de raíces clásicas, se cubren con vegetación; la mano femenina de las hermanas Doral se hacía presente especialmente en el comedor con abundante decoración floral y encajes en las telas de manteles y cortinas ${ }^{29}$.



Fig. 5. Comedor del hotel Covadonga. Oviedo. (Archivo Municipal de Oviedo)

Estos interiores contrastaban, en cambio, con la sobria elegancia del comedor de la Serrana, de gran sencillez, que se encuadra en el estilo de finales del XIX, con sus columnas de hierro fundido que lo compartimentan. El mobiliario con sillería thonet, contribuía también a esta imagen ya decimonónica de simplificada funcionalidad.

En el balneario de Las Caldas, el comedor principal, con dos grandes frentes de ventanal, estaba constituido por un gran salón rectangular, también con columnas de fundición en la zona central. Contaba con tres grandes muebles empotrados para el servicio de mesa, con vitrina en la parte superior y decorativas tallas en su coronación. Completaban este amueblamiento grandes mesas para platos y cubertería y las sillas de estrechos barrotes torneados. El suelo se cubría, con baldosa hidráulica de motivos florales. A pesar de que los comedores de los balnearios abandonaron más tarde la costumbre de la table $d^{\prime} h o t e^{30}$, Las Caldas había ya incorporado en estos inicios del siglo XX, la privacidad de las mesas independientes.

El comedor del hotel Gayoso de Luarca, el mejor establecimiento de una localidad que a principios de siglo disfrutaba de un movido tráfico de viajeros, tenía sin embargo un aspecto algo más popular. Con mesas independientes y 
sillas de madera con respaldo rectangular, una graciosa boiserie recorría la parte inferior de sus muros, con remate curvo y estética con dibujos decó, lo que daba un aire original a la estancia. Estos mismos motivos florales se repetían en las telas que adornaban una de las entradas. Componía el resto del mobiliario un aparador botellero y otro de vitrina, combinados y con idénticas tallas recargadas tipo restauración y mismo remate de dos aves enfrentadas. Uno de los aparadores, se adornaba en sus extremos con dos grandes muñecos de escayola, que durante mucho tiempo y tras sucesivas reformas, se conservaron en el comedor del hotel ${ }^{31}$.

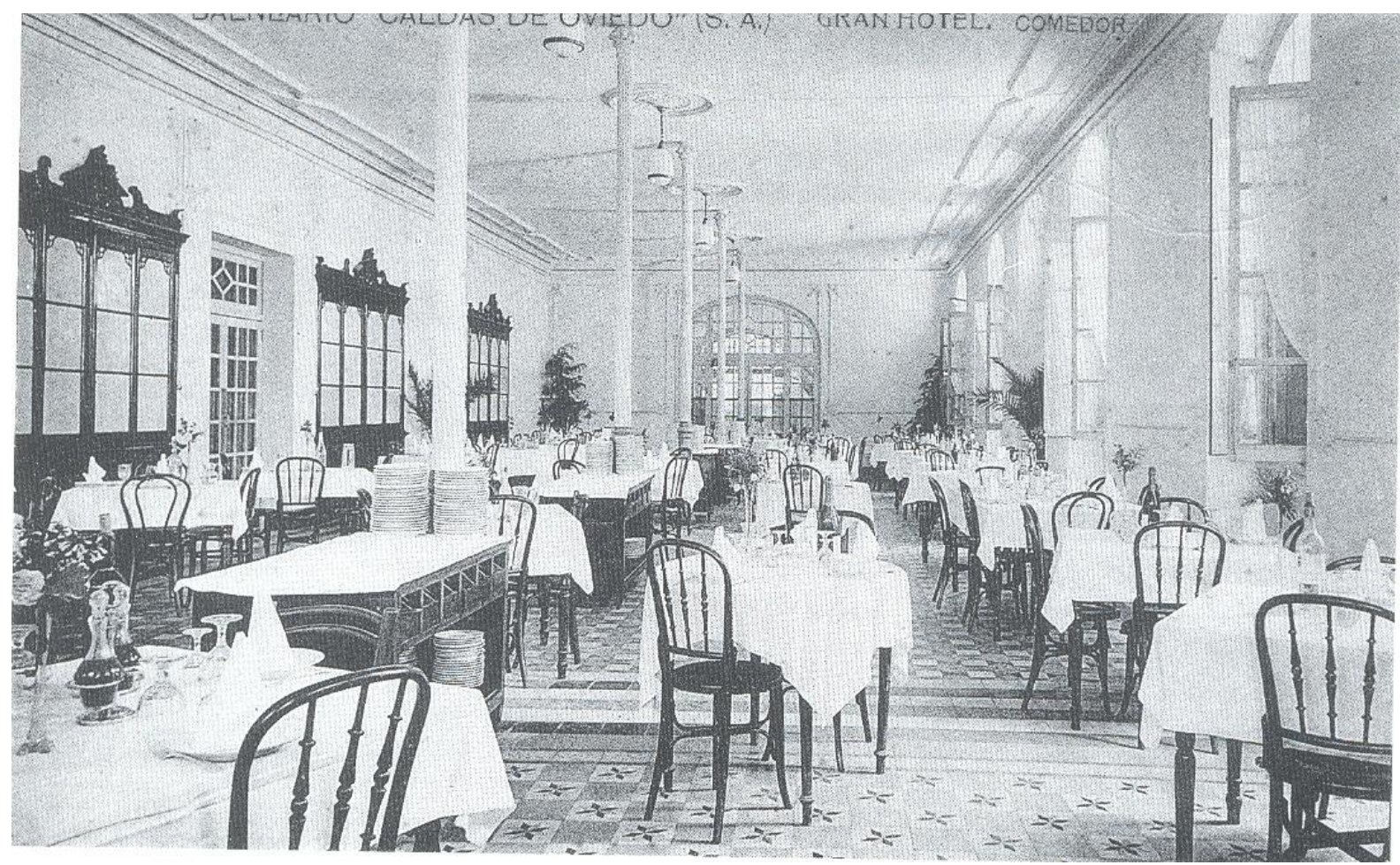

Fig. 6. Comedor del Balneario de Las Caldas. (Archivo familiar Álvarez-Buylla)

El examen de la disposición de estos comedores, en conclusión, muestra su profunda funcionalidad. Ni siquiera el lujo sugerido por su decoración y los detalles ornamentales del mobiliario o los paramentos pueden calificarse de superfluos, ya que cumplen la función de dotar de un clima de refinamiento a estas dependencias. Se ajustaban así a las exigencias de una clientela deseosa de rodearse durante su estancia en el hotel tanto de confort, como de indicios de lujo que denotasen su capacidad de consumo, e hicieran visible su posición en la escala social. La amplia gama de aparadores, vitrinas, mesas de servicio o muebles trincheros, a su vez, cumplían el papel de proveer con eficacia y funcionalidad de todo lo necesario a una mesa cada vez más exigente. La comida se rodeaba así de una significación socialmente compleja, a cuyo servicio se colocan unas infraestructuras especializadas. De hecho los comedores, dentro de la distribución general del hotel, van a ir estrechamente vinculados a la zona de 
servicio de la cocina, compuesta por office, despensa, y un largo etcétera de piezas y mobiliario. De modo que el restaurante se convierte en objeto de una atención especial por parte del arquitecto o del maestro de obras que tendrán especialmente en cuenta su relación y mejor conexión con estas dependencias de servicio, en bien del buen funcionamiento de todo lo relacionado con el servicio de mesa $^{32}$.

El recorrido por el restaurant de estos legendarios hoteles de la última década del siglo XIX y las primeras del siglo XX, y el análisis de su equipamiento, nos muestra de una forma meridiana, los importantes cambios que se iban a producir en los hábitos sociales en torno a la mesa en este periodo. Unos años marcados primero por una sociabilidad muchas veces impuesta, característica de los comedores decimonónicos con sus largas mesas donde todos los huéspedes compartían menú y conversación en un clima de estricta etiqueta. Para pasar pocos años más tarde a las mesas independientes, que daban respuesta a las exigencias de privacidad y de libertad en unos tiempos nuevos. Los hoteles, y sus hoteleros, siempre fieles a las exigencias de su clientela, van a adecuar y modernizar sus instalaciones al paso de los tiempos, a sus costumbres, a sus rituales... ofreciendo así al estudioso, un material espléndido para adentrarse en la cotidianidad de la vida y de los viajeros de entre-siglos.

\section{NOTAS}

\footnotetext{
${ }^{1}$ RODRÍGUEZ BERNÍS, Sofía, "Del martillo y el escoplo a la máquina de machihembrar. La industria del mueble en España en el siglo XIX”, en Espacio, tiempo y forma, Serie VIII, Ha del Arte, t. 12, 1999, pp. 368.

${ }^{2}$ RODRIGUEZ FERNÁNDEZ, Leire: “Creadores y difusores del gusto en la decoración de interiores de la Asturias finisecular: industrias, talleres y casas comerciales" en Decoración de interiores. Firmas, casas comerciales y diseño en Asturias (1880-1990), Oviedo, Septem ediciones, 2011, pp. 13-54. Se analizan aquí las diferentes industrias, talleres y casas comerciales asturianas vinculadas a este sector.

${ }^{3}$ Sobre los progresos del confort y de la higiene en el balneario de Panticosa véase la obra MONSERRAT ZAPATER, Octavio, El balneario de Panticosa (1826-1936), Diputación General de Aragón, Zaragoza, 1998 pp. 258-262.

${ }^{4}$ En RYBCZYNSKI, Witold, La casa: historia de una idea, Madrid, 1986. Este tema de la ventilación está muy bien tratado en el capítulo Luz y aire.

${ }^{5}$ AZORÍN, Obras completas, Madrid, M. Aguilar, editor, 1948, t. III, pp. 1250-51.

${ }^{6}$ WALLON, Armand, La vie quotidienne dans les villes d'eaux (1850-1914), Hachette, 1981, p.155.

${ }^{7}$ Todos los hoteles y fondas que aparecen en este catálogo comercial ofrecen como única foto la del comedor. Álbum Anunciador de Asturias, Imp. La Luarca, 1893.

${ }^{8}$ Los catálogos de productos de fábrica de Mieres de 1907 muestran un variado repertorio de columnas de hierro fundido, con abundantes elementos decorativos de raíces clásicas en todos sus elementos especialmente en capiteles. En FERNÁNDEZ MOLINA, José Ramón y GONZÁLEZ MORIYÓN, Juan, La Arquitectura del hierro en Asturias, 13 mercados y otros edificios urbanos, Asturias, 1994

${ }^{9}$ Toman el nombre estas sillas de su creador Michel Thonet (1796-1871). La producción de este mueblista austriaco y sus hermanos y sucesores, constituyen uno de los mejores ejemplos de industrialización aplicado al mueble moderno. Su producción fue cuantiosa, y la línea curva y el rizo se convertirían en un estilo autónomo. $\mathrm{Su}$ éxito aún mantiene el mobiliario Thonet en producción. Sobre este tema véase "Arquitectura. Las sillas
} 
Thonet cumplen 140 años", en La Voz del Interior on line, 4 de febrero de 2001.

${ }^{10}$ La central vienesa de esta empresa va a ceder la representación de sus creaciones a Thonet hermanos, de Madrid, pero sus modelos fueron también copiados en fábricas locales como las valencianas de Suay Bonora y de Salvador Albacar y Gil, hijos de Ventura Feliu y Joaquín Lleó. RODRÍGUEZ BERNÍS, Sofía, op. cit., p. 368.

${ }^{11}$ El Carbayón, 13 de abril de 1883. El anuncio sobre la construcción de este hotel se publica en diferentes números del periódico en los meses de abril y mayo de este año.

${ }^{12}$ AMO, Alzados del hotel Francés. “Oviedo $1^{\circ}$ de julio de 1881. El Arquitecto Javier Aguirre”. Exp. 3480/1881.

${ }^{13}$ Arrones Peón, Luis, Hostelería del viejo Oviedo, ed., La Nueva España, Oviedo, 1974, pp.113-117.

${ }^{14}$ Un ejemplo lo constituye el banquete celebrado en el año 1907 en el teatro Campoamor en honor del presidente del Centro Asturiano de la Habana, Sr. Bances, cuya reseña de prensa en primera página terminaba de esta forma: "[...] El banquete servido por el acreditado "Hotel Trannoy" resultó espléndido sobre toda ponderación. Merece nuestros plácemes más sinceros tan reputada casa”, en La Opinión Asturiana. Diario político. Año 1, no 31, 10 de octubre de 1907.

${ }^{15}$ En esta primera generación de hoteles que incluyen los aquí recientemente citados se carece de planos que permitieran saber su ubicación dentro del hotel. Sí se sabe que el del hotel Francés estaba en la planta baja. "Consta la edificación de piso terreno o sótano en donde se hallan las cocinas y sus dependencias, de un magnífico piso bajo en que están los comedores..." En El Carbayón, 13 de abril de 1883.

16 "Un café en el Oviedo de aquél tiempo, y "aquél tiempo", hace ya mucho, sesenta años, ochenta años, cien años, y aún más de cien... Por el ochocientos veinte, sonaba el Café de Chúcharo, en la calle de la Rúa [...] Estos cafés de estos tiempos eran botillerías a la vez. Podían ser lo que quisieran, porque indudablemente no eran nada. No se establecían en bajos; se establecían en primeros pisos y en ellos ni había sillones ni se conocían espejos....", en CABAL, Constantino, Contribución al Diccionario folklórico de Asturias. Apodo Arriero, Oviedo, 1984 (Edición facsimilar de la ed. Oviedo 1951), pp.240, 241.

${ }^{17}$ Almanaque del Carbayón, 1897.

${ }^{18}$ CABALLERO, Ricardo, y PALACIOS SUÁREZ, M., Guía ilustrada del viajero en Gijón, 1891, Gijón, 1891, p. 17.

${ }^{19}$ Dato ofrecido por Maruja Morán, hija de la propietaria.

${ }^{20}$ Información ofrecida por Concepción y Ceres, nietas de los fundadores, Francisca Méndez y José Antonio Artime.

${ }^{21}$ Se llamaba "callejón de Gayoso", y fue en un principio el acceso principal del hotel. Información ofrecida por Rosita, viuda de Balbino Gayoso.

${ }^{22}$ La boiserie (plural boiseries) es un término usado para definir a los paneles de madera en las paredes, que fueron muy populares en los interiores franceses durante los siglos XVII y XVIII. Diccionario de Terminología.

${ }^{23}$ Tarjeta postal. Archivo Museo del Pueblo de Asturias.

${ }^{24}$ Algunos espacios de ocio de la burguesía en la ciudad como el paseo y el café, se analizan en URÍA, Jorge Uría, Una historia social del ocio. Asturias 1898-1914, Madrid, Unión General de Trabajadores, 1996.

${ }^{25}$ Hotel Malet. Gijón. Vista parcial del comedor. AMG. Colección Postales, n. ${ }^{\circ} 1241$.

${ }^{26}$ Véase MASEY, Anne, El diseño de interiores en el siglo XX. Barcelona, 1998, pp. 31,32.

${ }^{27}$ El anuncio que aparece del hotel es un reportaje con fotografías y descripción de todas sus dependencias después de las obras de modernización. La Esfera, n. 343, año VII, Madrid, 1920.

${ }^{28}$ En este anuncio citado de la Esfera puede leerse: “...Su restaurant no ha descuidado el más ligero detalle, ...el hall lindísimo y muy coquetón, con su gran cristalera y sus preciosos muebles de junco, presenta un aspecto completamente elegante; el pensamiento del director es organizar en él tés selectos, ...-También merece especial mención la brasserie, que ha sido muy bien instalada, y una terrace comodísima... Todo en este hotel se ha puesto a la última exigencia..." La Esfera, n. 343, año VII, Madrid, 1920.

${ }^{29}$ De las cuatro hermanas Fernández Doral -una monja y otra viuda- serán la soltera y la casada con un médico (Cándida y Encarnación) las que se ocuparán del hotel. Información ofrecida por el padre Patac. En el año 1943 cogen el traspaso del hotel Principado y estarán al frente de este establecimiento hasta la década de los 70. AGPA. Hotel Principado, Exp. 15931/3.

${ }^{30}$ Una postal del Balneario de Fuensanta de estos años nos muestra su comedor con dos largas mesas alargadas, prueba de que la costumbre de la table d'hôte seguía en uso. Archivo del Museo del Pueblo de Asturias) 
${ }^{31}$ Foto del comedor. Archivo familiar Gayoso.

${ }^{32}$ ELEB, Monique, y DEBARRE Anne, L'invention de l'habitacion moderne, París 1880-1914, París, 1995, p. 113.

Fecha de recepción: 15 de octubre de 2014

Fecha de revisión: 27 de noviembre de 2014

Fecha de aceptación: 9 de diciembre de 2014 